\title{
Editorial
}

\section{Achievements of the Journal of Applied Oral Science in the 2010 and acknowledgments}

Dear authors, reviewers and readers,

It is time to remember the important achievements of the Journal of Applied Oral Science (JAOS), and once again acknowledge all of those who contributed to our success in 2010.

The main accomplishment of the JAOS was its inclusion, as the first journal from Latin America, in the Dentistry, Oral Surgery \& Medicine category of the 2009 Journal Citation Reports (JCR) Science Edition with an impact factor of 0.384 . As a natural consequence, there was an immediate increase in the number of submissions to the journal. This will demand changes in the editorial policies for 2011, which will be announced soon.

It is also a perfect time to thank all of those who supported the JAOS with important contributions either as reviewers or authors. We also have to thank the State of São Paulo Research Foundation (FAPESP), the National Council for Scientific and Technological Development (CNPq), the Foundation for the Coordination of Higher Education and Graduate Training (CAPES) and the University of Sao Paulo for their financial support. We always emphasize the JAOS is published by the Bauru School of Dentistry from the University of São Paulo, a non-profit making institution, so that the financial support from the federal and state governments is essential to our journal.

Please feel free to contact us through our e-mail address: jaos@usp.br. We also invite all readers, contributors and reviewers to visit our free complete online collection at http://www. scielo.br/jaos.

Finally, we take advantage of this editorial to wish all of happy holidays!

With our best regards,

\section{Carlos F. Santos}

DDS, MSc, PhD, Associate Professor

Editor-in-Chief

Journal of Applied Oral Science 